\section{Le日S \\ Gender Differences in Use of a Pedestrian Crossing: An Observational Study in
Newcastle upon Tyne}

\section{Eryn O'Dowd, Thomas V. Pollet,}

Department. of Psychology, Northumbria University, Newcastle upon Tyne, UK

"Author for correspondence (thomas.pollet@northumbria.ac.uk)

Evolutionary psychologists have put forward that there are evolved differences in risk taking between men and women. Potentially, these also play out in every day behaviours, such as in traffic. We hypothesised that (perceived) gender would influence using a pedestrian crossing. In addition, we also explored if a contextual factor, presence of daylight, could modify risk taking behaviour. 558 pedestrians were directly observed and their use of a crossing near a Metro station in a large city in the North East of England was coded. Using logistic regression, we found evidence that women were more inclined than men to use the crossing. We found no evidence for a contextual effect of daylight or an interaction between daylight and gender on use of the crossing. We discuss the limitations and implications of this finding with reference to literature on risk taking.

\section{Keywords}

gender differences, pedestrian, traffic

\section{Introduction}

Evolutionary psychologists have argued that there are evolved differences in risk taking between men and women (e.g., Daly \& Wilson, 2001; Wilson \& Daly, 1985). In line with this argument, there is a large body of evidence from various disciplines, ranging from economic decision making to traffic behaviour, supporting differences in risk taking between men and women. The size of this gender difference varies by factors such as age and context (e.g., Eckel \& Grossman, 2008; Kruger \& Nesse, 2006) but it appears fairly robust. Gender differences are, for example, evident from studies on financial risk taking (e.g., Olsen \& Cox, 2001; Powell \& Ansic, 1997). Similarly, this difference in risk taking propensity has been demonstrated in psychometric measures, with men typically scoring higher in measures relating to sensation seeking than women (e.g., Killgore, Grugle, Killgore, \& Balkin, 2010). A meta-analysis covering risk taking concluded that there is a gender difference in risk taking attitudes and behaviour but with the size varying in the domain studied
(Byrnes, Miller, \& Schafer, 1999).

These gender differences in risk taking have also been observed to play out in every day behaviour, such as in how we behave in traffic. Among other behaviours, men are less likely to wear a seatbelt than women (Calisir \& Lehto, 2002; Lerner et al., 2001). Men are also more likely to run red lights than women (e.g., Konecni, Ebbeson, \& Konecni, 1976) and, perhaps unsurprisingly, are more likely to be involved in (lethal) car accidents (e.g., Waylen \& McKenna, 2008). Also, in other traffic behaviours such as cycling (Cobey, Laan, Stulp, Buunk, \& Pollet, 2013; Pai \& Jou, 2014) or crossing (Pawlowski, Atwal, \& Dunbar, 2008) men are more likely than women to exhibit risktaking behaviour.

The current study primarily aims to conceptually replicate previous studies such as Pawlowski et al. (2008). It should be noted that multiple studies outside of evolutionary psychology have already suggested that gender differences in traffic behaviour exist, based on scenario studies (e.g., Holland \& Hill, 2007) as well as via direct observation (e.g., Tom \& Granié, 2011). Nonetheless, it is important to try and replicate such findings (Amir \& Sharon, 1990), especially given the current replication crisis. Here, we aim to replicate the finding on gender differences in every day risky behaviour among pedestrians crossing a busy road. In this particular situation, there is a risky but shorter route and a safer but longer route (Figure 1). We predict, that all else being equal, men will be more inclined to take the risky route than women. In addition, we explore if a contextual factor plays a role: the presence of daylight. We had no a priori hypotheses regarding the effect of daylight. On the one hand one could argue that darkness would facilitate norm violating behaviour (e.g., Zhong, Bohns, \& Gino, 2010). On the other hand, one could argue that the risks are greater when visibility is poor, therefore one might expect more norm compliance when there is no daylight. We also explore if this contextual factor interacts with gender.

\section{Methods}

\section{Procedure}

The first author observed 558 pedestrians (305 women) covertly from a parking near a metro station (Kingston Park) in Newcastle upon Tyne, a large city in the NorthEast of England, between December 2017 and March 2018. The final number of pedestrians was determined by the set number of hours to be coded (14h). Seven hours were coded in the morning between approximately 07:45am and 08:45am. Another seven hours were spent in the evening approximately between 5:00 pm and 6:00 pm. The times of day were chosen to correspond with peak commuting times into and out of Newcastle city centre. The first author unobtrusively coded the perceived gender and which path was taken (risky/safe) via use of an IPad. A 'safe' code was entered when a pedestrian fully used the designated 
crossing, whereas behaviour was coded as 'risky' when not fully using the crossing. In addition, the first author coded whether the observation was during daylight or not, based on www.sunsettimes.co.uk (accessed 23.04.18). Only individuals who appeared over 18 were coded (no groups/couples). In addition, only individuals for which gender could be visually assessed were coded. Individuals carrying large objects, pushing bikes, or prams were excluded from coding, as were individuals in wheelchairs or on mobility scooters. A subset $(n=67)$ was coded by a second coder and showed perfect correspondence for perceived gender and path taken (Cronbach's $\alpha=1$ ). The study was approved by the ethics committee where the first author was based.

\section{Statistical analyses}

Analyses were conducted in R 3.4.1 (R Development Core Team, 2008). We report a series of logistic regressions (Menard, 2002) and mosaic plots (Meyer, Zeileis, \& Hornik, 2006). The preregistration and code associated with this paper can be found on the OSF (https://osf.io/ tw7j9/). The associated code also contains additional analyses not reported in full here (e.g., Cochran-MantelHaenszel $(\mathrm{CMH})$ test for the stratified table (Cochran, 1954; Mantel \& Haenszel, 1959) and Bayes Factors for tabular analyses (Morey, Rouder, Jamil, \& Morey, 2015)).

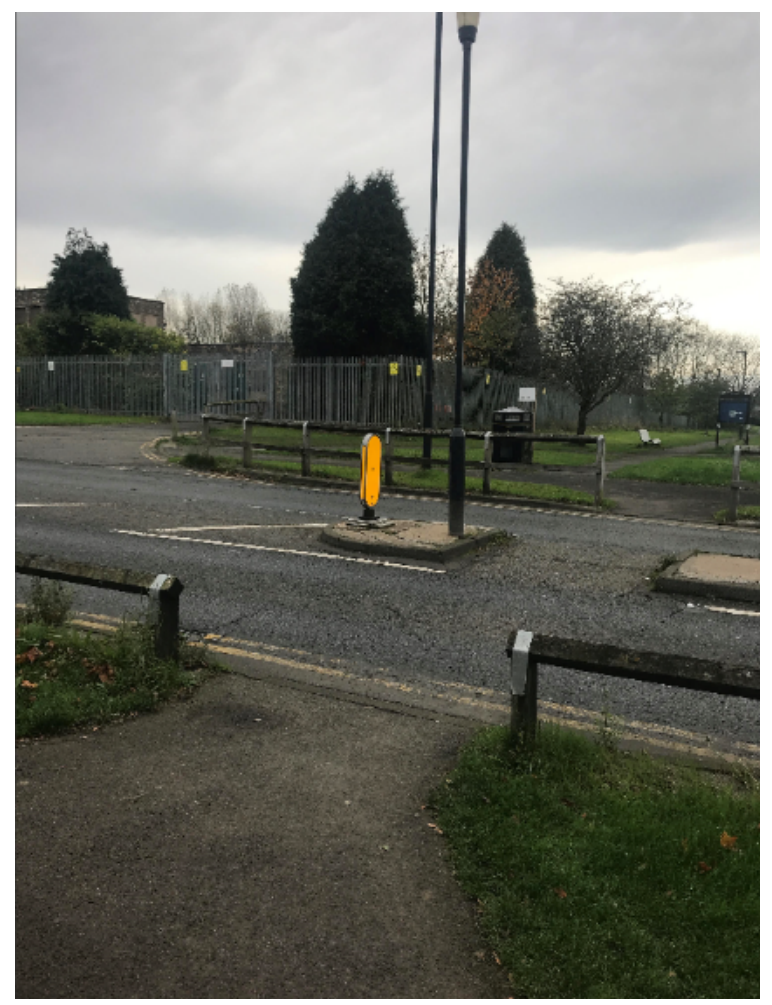

Figure 1. Observational site. The entrance to the metro station is to the left of the wooden shoulder. The safe route makes use of the crossing, the risky route is effectively 'jaywalking' between the metro entrance and the path.

\section{Results}

The odds ratios for the analyses are reported in Table 1 . Model 1 shows that gender was associated with taking the risky path. Men were more inclined to take the risky route than women were (Odds Ratio: 3.28, Figure 2). There was also a baseline association between daylight presence and route taking. Individuals were more inclined to take the safe route when daylight was present, compared to when it was not (Model 2, Odds Ratio: 1.49, Figure 3). In Model 3 , the association between daylight and risk taking was no longer statistically significant after incorporating gender, which remained statistically significant. Model 4 showed that there was no statistical evidence for an interaction effect. In the absence of daylight, men were relatively more inclined than women to take the risky route instead of the safe route (Odds Ratio (no daylight) $_{3.80 \text { vs. Odds Ratio }}$ (daylight): 2.85; Figure 4) but not statistically significantly so.

Table 1. Odds Ratios and model summaries from Logistic Regression Models.

\begin{tabular}{|c|c|c|c|c|}
\hline & $\begin{array}{l}\text { Outcome } \\
\text { (1) }\end{array}$ & (2) & (3) & (4) \\
\hline$\overline{\text { Male }}$ & $3.279^{* * *}$ & & $3.227^{* * *}$ & $2.854^{* * *}$ \\
\hline Not Daylight & & $1.485^{*}$ & 1.405 & 1.194 \\
\hline $\begin{array}{l}\text { Male* } \\
\text { Not Daylight }\end{array}$ & & & & 1.341 \\
\hline$N$ & 558 & 558 & 558 & 558 \\
\hline Log Likelihood & -332.928 & -351.434 & -331.327 & -331.034 \\
\hline AIC & 669.856 & 706.868 & 668.654 & 670.069 \\
\hline
\end{tabular}

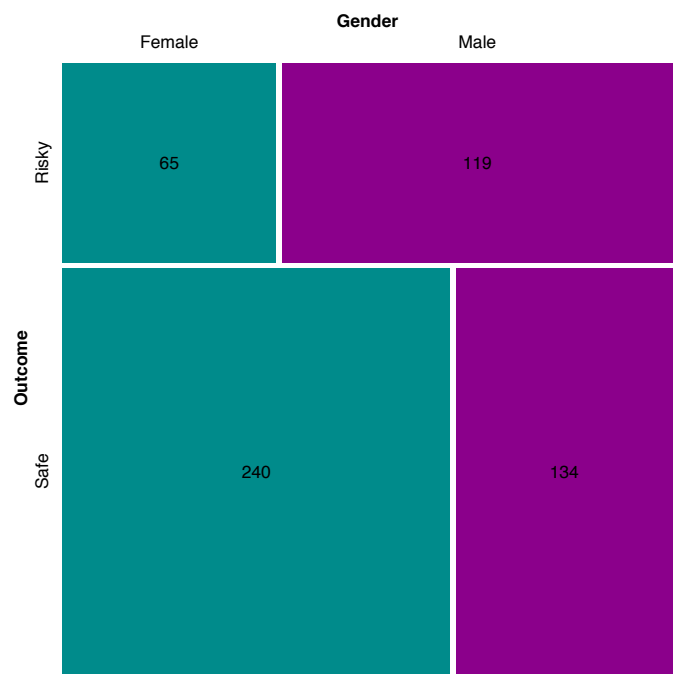

Figure 2. Mosaic plot for gender and risk taking.

\section{Discussion}

Our data further corroborated the existence of a gender difference in everyday risk taking in pedestrian behaviour (e.g., Holland \& Hill, 2007). In line with Cobey et al. (2013), there was a sizable difference between men and women in risk taking behaviour. Our study thus successfully replicates previous work in this area, and confirms the existence of gender differences in every day behaviour such as crossing the road. However, we found no evidence for a contextual effect. The presence of daylight did not significantly predict the route taken, after accounting for gender. Neither was there evidence for an interaction between gender and the presence or absence of daylight on risk taking behaviour. However, it should be noted that our study might have been underpowered to detect a subtle 


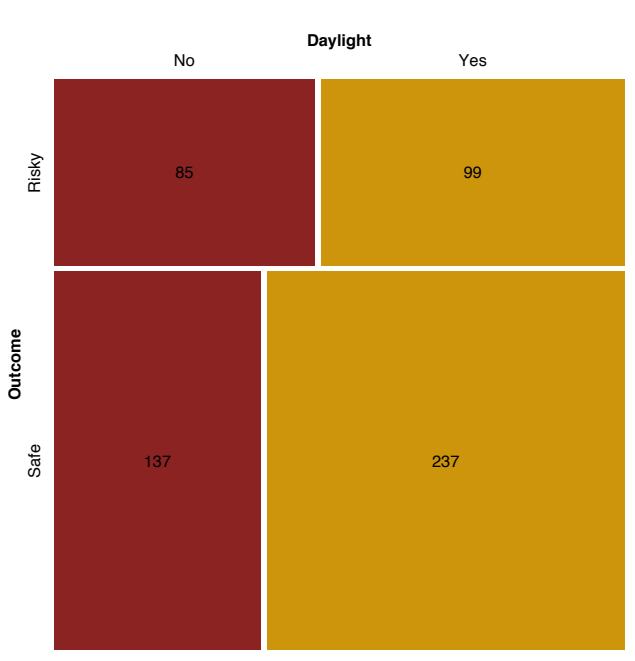

Figure 3. Mosaic plot for daytime and risk taking.

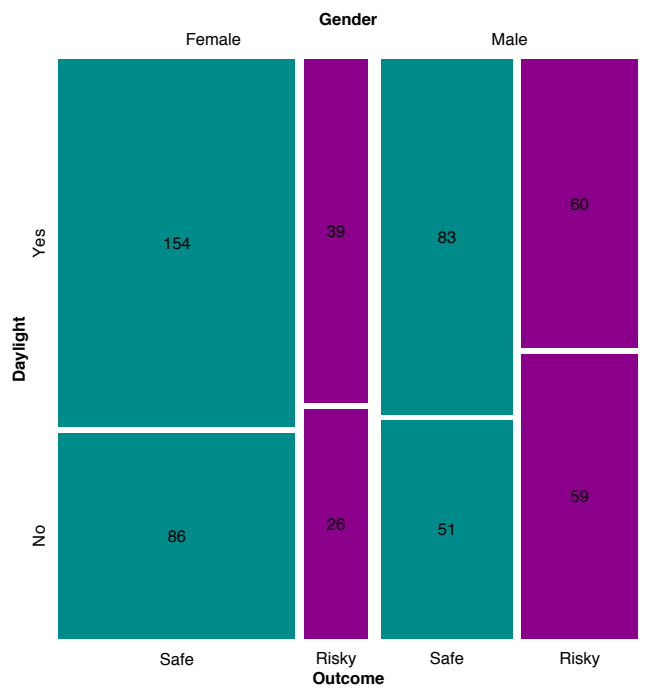

Figure 4. Mosaic plot for gender, daytime and risk taking.

interaction effect (Agresti, 2002: 240-ff).

There are several limitations to the current study. Firstly, our study was conducted in a 'WEIRD' society (Henrich, Heine, \& Norenzayan, 2010). The degree to which these findings on everyday risk taking behaviour would generalise to other urban settings, including those in non-Western societies, remains to be seen. Secondly, as the data are not from an experimental study it is possible that selection bias occurred. Outside of the context we observed, the pattern could be very different or even reversed. While our analysis on gender took into account potential confounding due to the time of day, albeit crudely via daylight presence or not, we cannot account for other confounders. As a consequence, it could very well be possible that outside the sampling window the patterns are reversed. However, it is also possible that we are underestimating the difference between the genders in every day risk taking. For now, we conclude that at least in this particular situation we are able to conceptually replicate previous findings on gender differences in risk taking. In future studies, we aim to further replicate the existence of these gender differences in other contexts. While we found no evidence for a contextual effect (daylight/ no daylight), perhaps in other contexts the gender difference in risk taking would be more or less pronounced (for example, a metro station in a safe neighbourhood versus one in an unsafe neighbourhood). Next, we should note that, in this study, we are unable to differentiate between risk taking behaviour and norm compliance. It could be that we have observed norm compliance, or another behaviour, rather than directly observing risk taking behaviour. We have assumed that in this particular situation norm compliance, using the crossing, is the inverse of risk taking behaviour. Yet, given that many instances were recorded where the pedestrian took the unsafe route, we can question whether this really constitutes meaningful risk taking behaviour. In future studies, it would be worthwhile to investigate multiple sites which might allow for a better differentiation between risk taking behaviour and norm compliance. For example, variation in how risky the situation is, and/or whether norms are salient could allow to better disentangle whether the behaviour in question is better characterized as one or the other.

Finally, we call for more applied research examining behaviour in the real world (Baumeister, Vohs, \& Funder, 2007). While there might be limits to the inferences one can make via direct observation (Eibl-Eibesfeldt, 1979), it is nonetheless a valuable tool for applied evolutionary psychology (Roberts, 2012) and a valuable research experience for a bachelor project (Boice, 1983).

\section{Acknowledgement}

This paper is based on the first author's Bachelor thesis.

\section{References}

Agresti, A. (2002). Categorical data analysis (2nd ed.). New York, NY: John Wiley \& Sons.

Amir, Y., \& Sharon, I. (1990). Replication research: A "must" for the scientific advancement of psychology. Journal of Social Behavior and Personality, 5, 51-69.

Baumeister, R. F., Vohs, K. D., \& Funder, D. C. (2007). Psychology as the science of self-reports and finger movements: Whatever happened to actual behavior? Perspectives on Psychological Science, 2, 396-403. (doi: 10.1111/j.1745-6916.2007.00051.x)

Boice, R. (1983). Observational skills. Psychological Bulletin, 93, 3-29. (doi: 10.1037/0033-2909.93.1.3)

Byrnes, J. P., Miller, D. C., \& Schafer, W. D. (1999). Gender differences in risk taking: A meta-analysis. Psychological Bulletin, 125, 367-383. (doi: 10.1037/00332909.125.3.367)

Calisir, F., \& Lehto, M. R. (2002). Young drivers' decision making and safety belt use. Accident Analysis \& Prevention, 34, 793-805. (doi: 10.1016/S00014575(01)00079-3)

Cobey, K. D., Laan, F., Stulp, G., Buunk, A. P., \& Pollet, T. V. (2013). Sex differences in risk taking behavior among Dutch cyclists. Evolutionary Psychology, 11, 147470491301100. (doi: 10.1177/147470491301100206)

Cochran, W. G. (1954). Some methods for strengthening the common $\chi^{2}$ tests. Biometrics, 10, 417-451. (doi: 10.2307/3001616)

Daly, M., \& Wilson, M. (2001). Risk-taking, intrasexual competition, and homicide. Nebraska Symposium on 
Motivation, 47, 1-36. Retrieved from http://www.ncbi. nlm.nih.gov/pubmed/11759345 (accessed 23.04.18)

Eckel, C. C., \& Grossman, P. J. (2008). Chapter 113 Men, women and risk aversion: Experimental evidence. In C. R. Plott \& V. L. Smith (Eds.), Handbook of Experimental Economics Results (Vol. 1, pp. 1061-1073). Elsevier. (doi: 10.1016/S1574-0722(07)00113-8)

Eibl-Eibesfeldt, I. (1979). Human ethology: Methods and limits. Behavioral and Brain Sciences, 2, 50-57. (doi: 10.1017/S0140525X00060696)

Henrich, J., Heine, S. J., \& Norenzayan, A. (2010). The weirdest people in the world? Behavioral and Brain Sciences, 33, 61-83. (doi: 10.1017/ S0140525X0999152X)

Holland, C., \& Hill, R. (2007). The effect of age, gender and driver status on pedestrians' intentions to cross the road in risky situations. Accident Analysis \& Prevention, 39, 224-237. (doi: 10.1016/j.aap.2006.07.003)

Killgore, W. D. S., Grugle, N. L., Killgore, D. B., \& Balkin, T. J. (2010). Sex differences in self-reported risk-taking propensity on the evaluation of risks scale. Psychological Reports, 106, 693-700. (doi: 10.2466/ pr0.106.3.693-700)

Konecni, V., Ebbeson, E. B., \& Konecni, D. K. (1976). Decision processes and risk taking in traffic: Driver response to the onset of yellow light. Journal of Applied Psychology, 61, 359-367. (doi: 10.1037//00219010.61.3.359)

Kruger, D. J., \& Nesse, R. M. (2006). An evolutionary life-history framework for understanding sex differences in human mortality rates. Human Nature, 17, 74-97. (doi: 10.1007/s12110-006-1021-z)

Lerner, E. B., Jehle, D. V. K., Billittier IV, A. J., Moscati, R. M., Connery, C. M., \& Stiller, G. (2001). The influence of demographic factors on seatbelt use by adults injured in motor vehicle crashes. Accident Analysis \& Prevention, 33, 659-662. (doi: 10.1016/S00014575(00)00080-4)

Mantel, N., \& Haenszel, W. (1959). Statistical aspects of the analysis of data from retrospective studies. Journal of the National Cancer Institute, 22, 719-748. (doi: 10.1093/jnci/22.4.719)

Menard, S. (2002). Applied logistic regression analysis. London, UK: Sage.

Meyer, D., Zeileis, A., \& Hornik, K. (2006). The strucplot framework: Visualizing multi-way contingency tables with ved. Journal of Statistical Software, 17, 1-48. Retrieved from http://www.jstatsoft.org/v17/i03/paper (accessed 23.04.18)

Morey, R. D., Rouder, J. N., Jamil, T. (2015). Package "BayesFactor." URL < Http://cran. R-Project. org/web/ packages/BayesFactor/BayesFactor. Pdf $>$ (accessed 10.06.15).

Olsen, R. A., \& Cox, C. M. (2001). The influence of gender on the perception and response to investment risk: The case of professional investors. Journal of Psychology and Financial Markets, 2, 29-36. (doi: 10.1207/ S15327760JPFM0201_3)

Pai, C.-W., \& Jou, R.-C. (2014). Cyclists' red-light running behaviours: An examination of risk-taking, opportunistic, and law-obeying behaviours. Accident Analysis \& Prevention, 62, 191-198. (doi: 10.1016/ j.aap.2013.09.008)

Pawlowski, B., Atwal, R., \& Dunbar, R. I. M. (2008). Sex differences in everyday risk-taking behavior in humans. Evolutionary Psychology, 6, 147470490800600. (doi: $10.1177 / 147470490800600104)$
Powell, M., \& Ansic, D. (1997). Gender differences in risk behaviour in financial decision-making: An experimental analysis. Journal of Economic Psychology, 18, 605-628. (doi: 10.1016/S0167-4870(97)00026-3)

R Development Core Team. (2008). R: A language and environment for statistical computing. Vienna, Austria: R Foundation for Statistical Computing.

Roberts, S. C. (2012). Applied evolutionary psychology. Oxford, UK: Oxford University Press.

Tom, A., \& Granié, M.-A. (2011). Gender differences in pedestrian rule compliance and visual search at signalized and unsignalized crossroads. Accident Analysis \& Prevention, 43, 1794-1801. (doi: 10.1016/ j.aap.2011.04.012)

Waylen, A. E., \& McKenna, F. P. (2008). Risky attitudes towards road use in pre-drivers. Accident Analysis \& Prevention, 40, 905-911. (doi: 10.1016/ j.aap.2007.10.005)

Wilson, M., \& Daly, M. (1985). Competitiveness, risk taking, and violence: The young male syndrome. Ethology and Sociobiology, 6, 59-73. (doi: 10.1016/01623095(85)90041-X)

Zhong, C.-B., Bohns, V. K., \& Gino, F. (2010). Good lamps are the best police: Darkness increases dishonesty and self-interested behavior. Psychological Science, 21, 311-314. (doi: 10.1177/0956797609360754) 